\title{
Roller Bench Design for Measurement of Effective Engine Power
}

\author{
I. Lakatos, P. Dely \\ Széchenyi István University, Department of Road and Rail Vehicle \\ Egyetem tér 1, H-9026, Győr, Hungary \\ e-mail: lakatos@sze.hu
}

Abstract: Effective performance of road vehicle engines represents an important segment of vehicle specification. A specific measurement method is required for acquisition and assessment of data coming from diagnostic tools attached to the rolling road. A new method has been elaborated by the first author. This method can be used as a measurement system to measure effective engine power for operational diagnostic purposes. Free rollers are needed instead of loading machine, according to the new approach. This article demonstrates the design principles for the roller bench needed.

Keywords: drive train, wheel performance, effective performance, free acceleration

\section{Introduction}

The principle of the measurement method is to accelerate and decelerate the unloaded drive train of the studied vehicle on free rollers (there is no need for a rolling road). Since the decision to measure external characteristics, the measurement must be performed under total load conditions [1, 2, 3, 4, 5, 10].

The kinetic energy change of the system is displayed in the acceleration of the wheel and the rollers, so this element equals to the wheel performance $\left(P_{k}\right)$. Though the diverted heat equals to the running loss performance $\left(P_{v}\right)$ :

$$
P_{e}=P_{k}+P_{v}
$$

The basic dynamic equation of rotation can be described both for acceleration and deceleration phases:

$$
P=\mathrm{M} \omega=\left(\theta_{\text {red }} \varepsilon\right) \omega=\theta_{\text {red }} \frac{d^{2} \varphi}{d t^{2}} \frac{d \varphi}{d t}
$$


where:

- $\omega$ is the angular velocity of the roller of the rolling road;

- $\Theta_{\text {red }}$ is moment of inertia of the drivetrain of the vehicle reduced to the axis of the roller of the rolling road;

- $\varphi \quad$ is angle of rotation of the rollers;

- $\varepsilon \quad$ is angular acceleration of the rollers;

- $t$ is time.

\section{Theoretical background of the new measurement method}

The phases of the measurement are followings:

- Acceleration phase: the drive train of the vehicle on the bench and the rollers of the rolling road are accelerated in the studied gear, up to the rated engine speed with full load (on full blast).

- Deceleration phase: by releasing the clutch, leaving the gear at the given position, we let the car decelerate until it stops.

During the measurement, as there is no external load, the engine has to accelerate the moments of inertia indicated. During deceleration phase the moment of inertia of the engine is separated, so with this exemption the rest of the moments of inertia decelerate the system.

During the test, the angular velocity and the angular acceleration values of the roller are recorded exclusively, see equation (2). In order to calculate power, the moment of inertia of the drivetrain reduced to the roller axis is needed.

According to the aforementioned measurements the diagram displayed in Fig. 1. can be recorded.

\section{Constituents of power}

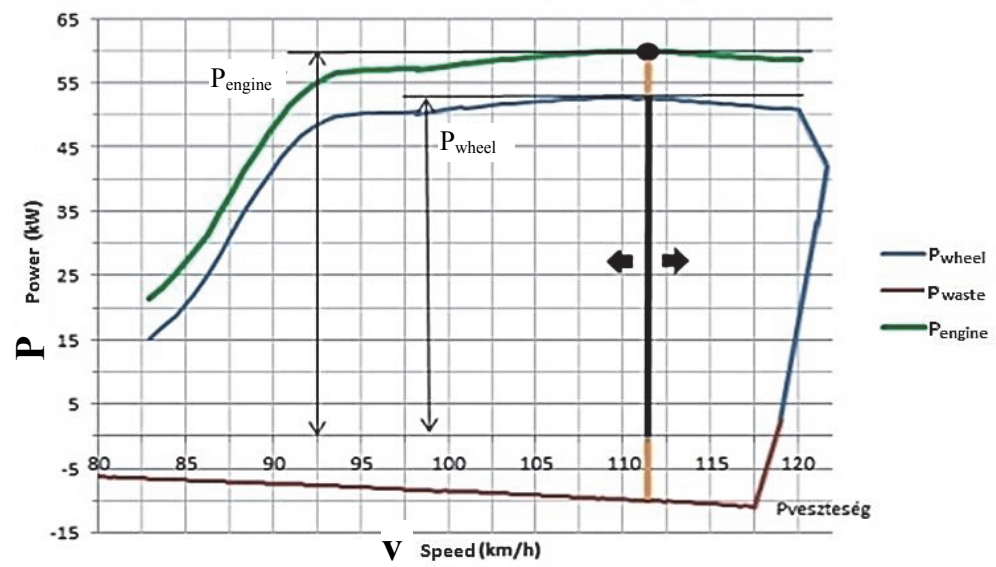

Figure 1. Characteristic curve recorded during the measurement 
As can be seen in Fig. 1., the effective power of the engine is calculated as the sum of the wheel power and the waste power. Because the moment of inertia of the drivetrain is unknown, the power constituent values have to be determined by measurement.

The new measurement technology solves the above problem by means of an additive mass. Thus, the necessity of a loading machine in the roller bed can be eliminated and the price of the roller bench can be reduced significantly.

\section{Validating the external characteristic curve of the engine without rolling road test (new measurement method)}

The main points of the measurement method which has been elaborated are as follows:

In case of not possessing a rolling road just a roller bed two free acceleration measurements have to be conducted.

Therefore, an additive mass is needed to perform the measurement. The layout of the Schenck W280 roller bench with rotating mass in the department laboratory is shown in Fig. 2.

In this case, the additive mass is not detachable, consequently, it needs to be modified in order to adapt the machine to the new measurement. After the modification, diagrams in Fig 3. can be produced.

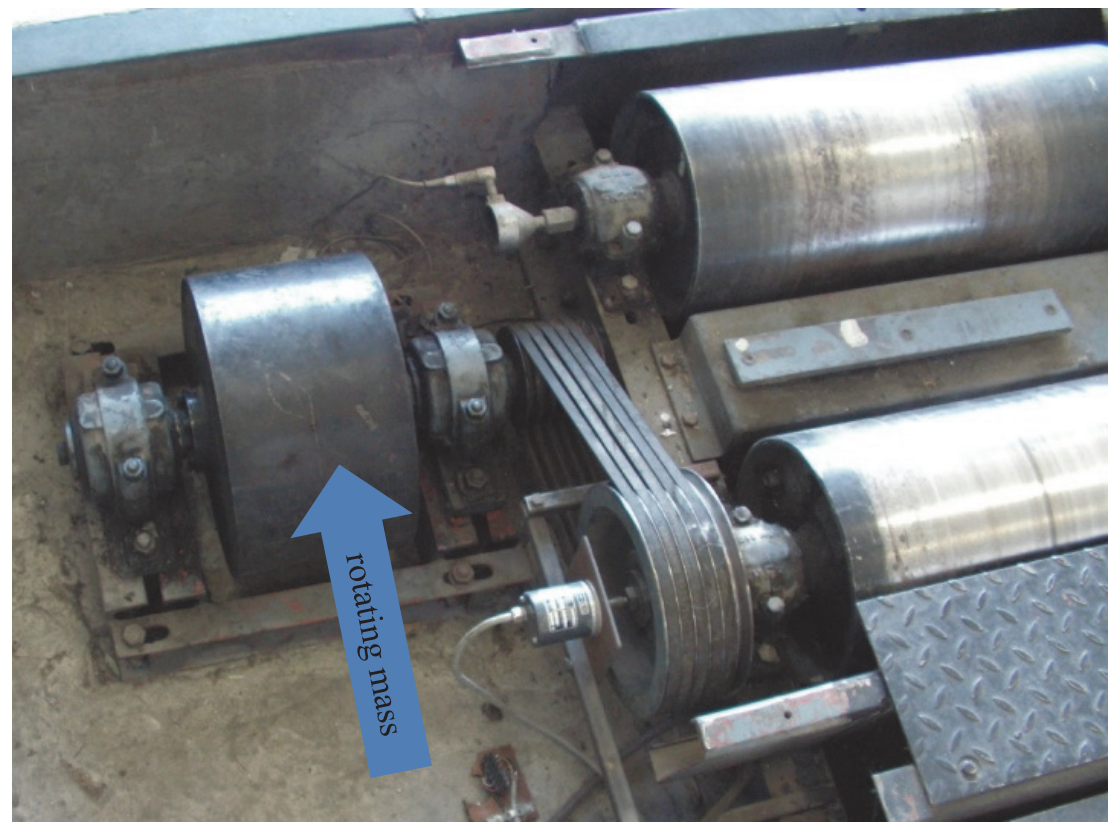

Figure 2. Roller bench with the rotating mass 
$\omega, \varepsilon$

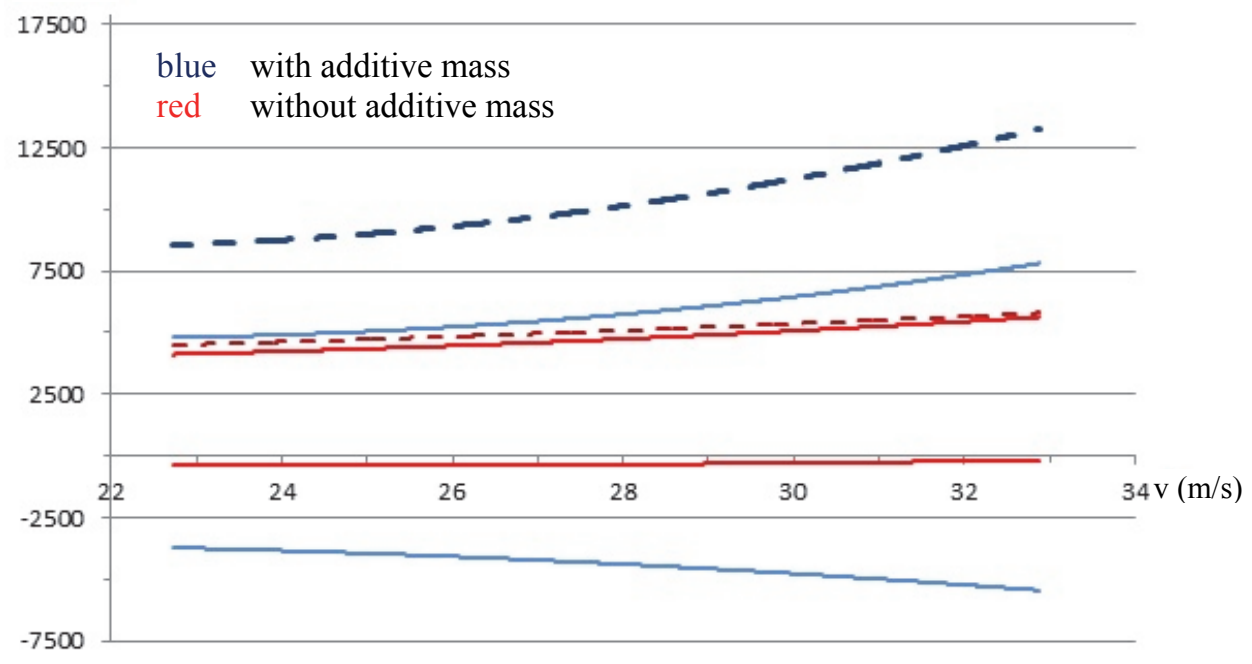

Figure 3. Diagrams of two subsequent measurements

\section{Rundown experiments with additive mass}

The engine is running at a given speed (i.e. in the given case is the $2 / 3$ of the nominal engine speed value) and then the fuel supply is stopped. The speed of the engine gradually decreases and it comes to a halt.

The measurement was performed in one given gearshift lever position, with additive mass in the first run and without mass in the second. Both measurements produced a graph of free rundown. Considering the Fig. 4. two graphs, it is now possible to calculate the moment of inertia of the drivetrain.

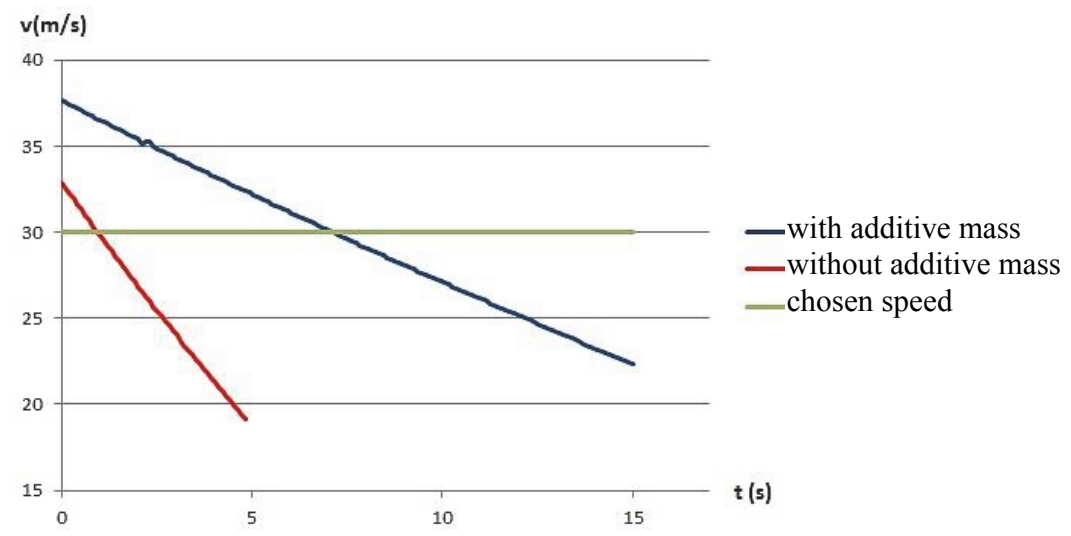

Figure 4. Rundown graphs 
It can easily be observed that the rundown time of the system is significantly longer when the additive mass is coupled to the rollers (Fig. 5.).

\section{Modification of the SCHENCK W 280 type roller bench into detachable- additive-mass type}

\subsection{Selection of electromagnetic clutch}

When using the aforementioned new measurement method it is imperative that one should be able to couple or decouple the additive mass by means of a clutch easily. The optimum solution for the above purpose is offered by an electromagnetically controlled clutch. The transfer of the required torque depends on the moment of inertia of the flywheel and on the maximum acceleration value.

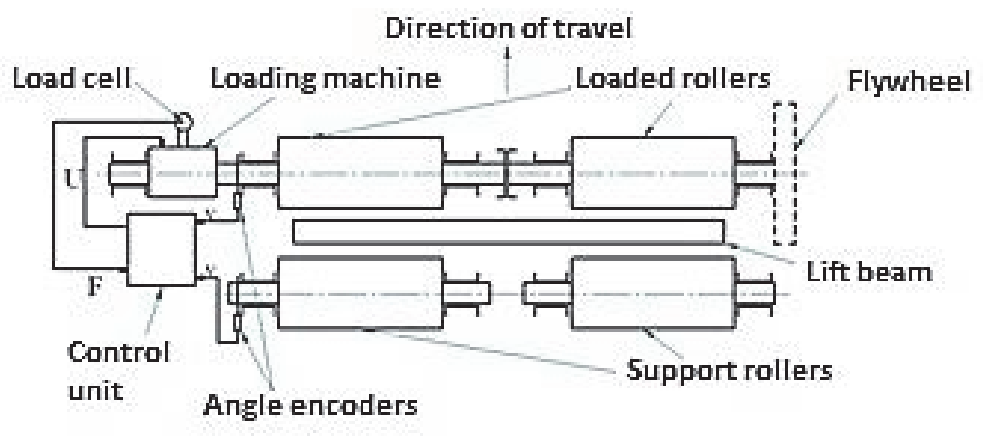

Figure 5. Layout of the roller bench

The appropriate clutch size can be calculated based on the maximum acceleration value of the vehicle.

The clutch must be built into the drive pulley of the flywheel of the present roller bed.

After the modification, there is no need any serious interference to couple or decouple the additive mass to or from the rollers, just a suitable electronic control unit with a software is needed.

\subsection{Modification of the roller bench}

During the modification of the roller bench, the present pulley must be modified in order to enable the mounting of the electromagnetic clutch inside (Fig 6.). 


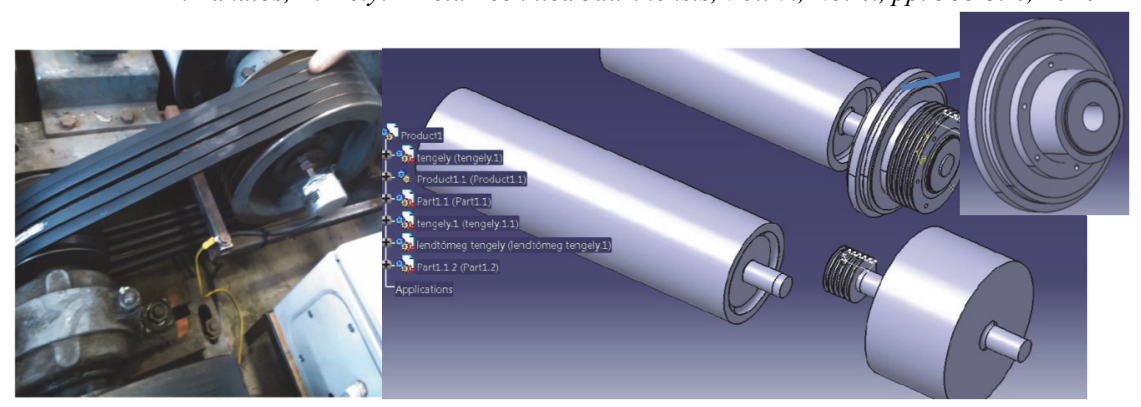

Figure 6. Design of possible layout of electromagnetic clutch

The roller bench modified or built according to the design (shown in fig. 6.) is capable of measuring the effective power of a vehicle engine. Provided, the additive mass and appropriate measurement software is used. The main advantage of the method is that high measurement accuracy can be achieved with the help of diagnostic tools and a budget-saving machinery.

\section{Summary}

Several advantages emerge with elaborating a new measurement system $[6,7,8,9,11$, 12, 13]:

- There is no need for rolling road, therefore simpler and cheaper measurement devices can be developed.

- The measurement is more accurate since empirical correction factors are excluded from the calculations.

The new method described in the present article provides an available opportunity for professional garages, as it is capable of defining the diagnostic performance of the engine with the required accuracy.

It is a very important achievement that with the help of diagnostic tools (without removal of the engine) an exact result of the effective performance of the engine can be achieved, as it significantly differs from the performance result of the wheels that can be measured on the rolling road (Fig. 5.)

\section{Acknowledgement}

TÁMOP-4.2.4.A/2-11/1-2012-0001 identification number of the National Excellence Program - was the establishment and operation system for domestic students, researchers and staff support as a priority project by the convergence program. The project is funded by the EU, the European Social Fund co-funded. 


\section{References}

[1] Lakatos, I.: Analyse der Zusammenhängen zwischen indizierten Motorkennwertwen und Rollprüfstanduntersuchungsergebnissen, Jármüvek, vol. 49, no. 6, pp. 31-34, 2002

[2] Lakatos, I.: Comparative measures on rolling road dynamometers, XXV. microCAD International Scientific Conference, Miskolc, Hungary, pp. 57-64, 2011

[3] Lakatos, I.: Gasoline engine diagnostic on chassis dynamometers, XIX. microCAD International Scientific Conference, Miskolc, Hungary, pp. 27-32, 2010

[4] Lakatos, I.: Instacioner Engine Performance Measure on Rolling Road Dynamometers, XIX. microCAD International Scientific Conference, Miskolc, Hungary, pp. 33-38, 2010

[5] Lakatos, I.: Measuring Engine Performance with Diagnostic Tools, Innovation and Sustainable Surface Transportation Conference, Budapest, Hungary, CD proceeding, 2010

[6] Péter, T.: Reduction of parameters of spatial non-linear vehicle swinging systems, for identification and optimisation purposes, Perodica Polytechnica: Transportation Engineering, vol. 16, no. 1-2, pp. 131-141, 1988

[7] Péter, T., Bokor, J.: Modeling of vehicle traffic systems and research of their control (in Hungarian), A Jövő Jármüve: Jármüipari Innováció, vol. 1, no.1-2, pp. 19-23, 2006

[8] Peter, T, Bellay, A.: Integral Transformations of Road Profile Excitation for Variable Vehicle Speeds, Vehicle Systems Dynamics, vol. 15, no. 1, pp. 19-40, 1986

[9] Péter, T.: Fuzzy and Anytime Signal Processing Approaches for Supporting Modeling and Control, In: Rudas I.J. (ed.), ICCC 2005: IEEE 3rd International Conference on Computational Cybernetics, pp. 339-344, 2005 DOI: 10.1109/ICCCYB.2005.1511598

[10] Lakatos, I.: Diagnostic measurement for the effective performance of motor vehicles, Acta Polytechnica Hungarica, vol. 10, no. 3, pp. 239-249, 2013

DOI: 10.12700/APH.10.03.2013.3.16

[11] Gáspár, P., Bokor, J., Szabó, Z., Fülep, T., Szauter, F., Mihály, A.: Integrated robust control design for in-wheel-motor vehicles, FISITA 2014 World Automotive Congress, 2-6 June 2014, Maastricht, 2014

[12] Zezyulin, D.V., Makarov, V., Ogorodnov, S., Belyakov, V.: Methodology of Roadway Impacts Modelling to Predict the Fatigue Life of Vehicles Parts, Acta Technica Jauriensis, vol. 7, no. 3, pp 267-279, 2014

DOI: 10.14513/actatechjaur.v7.n3.277

[13] Szauter, F., Péter, T., Bokor, J.: Examination of Complex Traffic Dynamic Systems, Acta Technica Jaurinensis Series Transitus, vol. 6, no. 3, pp 136-142, 2013 